Preference is given to letters commenting on contributions published recently in the JRSM. They should not exceed 300 words and should be typed double spaced

\section{The health of Gulf War veterans}

Professor Lee and colleagues (October $2002 \quad J R S M^{1}$ ) presented their findings in 1000 Gulf War veterans who came to their programme for medical advice, and combined the data with those from two previous surveys, each of 1000 veterans, by Coker et $a .^{2}$ and their own group ${ }^{3}$. I question the methodology and statistical models adopted by Lee et al. in their two papers ${ }^{1,3}$.

First, why did they not adhere to the reviewing criteria adopted in the first paper by Coker? Introduction of the term 'wellness' serves to confuse. There is no differentiation between individuals who were well when they attended and those who considered that they were unwell. Second, would it not have been better to adhere to Chapter 18 diagnosis (International Statistical Classification of Diseases) throughout the series, with appropriate comment? To change the criteria between papers prevents comparison of like with like. Third, whilst chronic fatigue syndrome (CFS) is included in the initial paper-87 diagnosed with the syndrome - it has been abandoned by Lee et al., despite the predominance of relevant symptoms. 'Multiple unexplained physical symptoms' and somatic disorders are included, which have no accepted criteria.

The major concern is the inclusion of 1057 individuals who were well by any definition and attended for reassurance, information, etc. This fundamentally distorts the statistics: overall, the percentages should be taken not from 3000 but from the 1943 individuals who attended because they felt ill. If the Chapter 21 individuals are extracted from Table 2, this leaves 837 ill in the first 1000, 494 in the second 1000 and 612 in the third 1000. Affective symptoms are then, respectively, 59\% (from 50\%), 98\% (from 49\%) and 62\% (from 38\%); fatigue 50\% (from $42 \%$ ), 91\% (from 45\%) and 42\% (from 26\%). This is reflected throughout. Table 3 then becomes uninterpretable. Table 5 should be based on 1943 individuals and is effectively distorted by $50 \%$ - thus, post-traumatic stress disorder (PTSD) becomes 19\% (from 12\%), depression 9\% (from 6\%) and so on.

Even if we allow for the self-selection in the veterans seen by Lee et al. there is a major discrepancy regarding PTSD between this cohort and the series reported a few weeks later by Wessely's group in the $B M J^{4}$. In Lee's paper the prevalence is said to be $12 \%$ but should be $19 \%$, as I have shown; in Wessely's paper it is no more than $3 \%$. Could the explanation be that Lee et al. dropped CFS from the reviewing criteria used by Coker et al.? Should many of their PTSD diagnoses have been CFS?
Because of these aberrations, the two papers by Lee et al. contribute little to the understanding of illnesses affecting Gulf War veterans.

A H Wilson-Ing

Erw Lon, Pentre Galar, Crymych, Pembrokeshire SA41 3QP, UK

\section{REFERENCES}

1 Lee HA, Gabriel R, Bolton JPG, Bale AJ, Jackson M. Health status and clinical diagnoses of 3000 Gulf War veterans. J R Soc Med 2002;95: $491-7$

2 Coker WJ, Bhat BM, Blatchley NF, Graham JT. Clinical findings for the first 1000 Gulf War veterans in the Ministry of Defence's medical assessment programme. BMJ 1999;318:290-4

3 Lee HA, Gabriel R, Bale AJ, Bolton P, Blatchley NF. Clinical findings of the second 1000 UK Gulf War veterans who attended the Ministry of Defence's medical assessment programme. JRAMC 2001; 147:153-60

4 Ismail K, Kent K, Brugha $\mathrm{T}$, et al. The mental health of UK Gulf War veterans: phase 2 of a two phase cohort study. BMJ 2002;325:576-81

\section{Authors' reply}

As is made clear in our paper, the intent was to review the diagnoses of all 3000 who attended and to make some assessment of wellbeing, as detailed by Lee et al ${ }^{1}$. Those attending the Gulf Veterans' Medical Assessment Programme (GVMAP) are referred by their medical attendants on the basis that they have health concerns relating to their service in the Gulf. It is therefore appropriate to include all 3000 referred, as the population in which the prevalence of diseases found is expressed rather than restricting the population denominator to just those found to be ill. When one discusses the prevalence of disease in a population, one usually includes the whole population as the denominator rather than just the unwell portion. This addresses WilsonIng's concern that we have fundamentally distorted the statistics.

Wilson-Ing further suggests that we have changed diagnostic criteria because of the reduction of Chapter 18 diagnoses. The first point to make is that the bridging 100 exercise in our first paper ${ }^{1}$ was designed to compare the diagnostic criteria between that paper and that of Coker et $a 1^{2}$. Secondly, it is hardly surprising that the diagnostic pattern is different, given both the time that has elapsed and the considerable research effort that has gone into Gulf veterans' illnesses without finding any convincing evidence of unique Gulf-related illness. To suggest that the diagnosis of chronic fatigue syndrome (CFS) has been abandoned by us is disingenuous, since Wilson-Ing is not in a position to make clinical diagnoses on our series. We, who have seen the patients, are satisfied that the symptoms presented do not amount to chronic fatigue syndrome ${ }^{3,4}$. We have certainly not included medically unexplained physical 
symptoms or somatic disorders in our diagnoses, but have discussed these aspects in the discussion section of the paper. We would suggest that the references therein provide the background and criteria for our discussion.

In his comments about PTSD, Wilson-Ing is falling into the trap of not comparing like with like. Since PTSD is associated with exposure to trauma, it is likely that we would see more of it, since we were reporting upon the diagnoses of a group of military veterans who had health concerns as a result of their service in a conflict, than Ismail would find in a study examining the mental health of a sample of the whole Gulf veteran population which includes those with no health concerns ${ }^{5}$. The analogy is to claim that there is a higher prevalence of lung cancer among patients attending a chest clinic than amongst the general population. The suggestion that the alleged excess of PTSD may be misdiagnosed CFS rather misses the point, explicitly stated in our paper, that the suggested diagnoses of PTSD were confirmed by consultant psychiatrists.

\section{Harry A Lee}

Roger Gabriel

J Philip G Bolton ${ }^{1}$

Amanda J Bale

Mark Jackson

Gulf Veterans' Medical Assessment Programme, Baird Health Centre, St Thomas' Hospital, London SE1 7EH; 'Gulf Veterans' IIInesses Unit, Ministry of Defence, St Christopher House, London SE1 OTD, UK

\section{REFERENCES}

1 Lee HA, Gabriel R, Bale AJ, Bolton P, Blatchley NF. Clinical findings of the second 1000 UK Gulf War veterans who attended the Ministry of Defence's Medical Assessment Programme. JRAMC 2001;147:153-60

2 Coker WJ, Bhatt BM, Blatchley NF, Graham JT. Clinical findings for the first 1000 Gulf War veterans in the Ministry of Defence's medical assessment programme. BMJ 1999;318:290-4

3 Chronic Fatigue Syndrome. Report of a Joint Working Group of the Royal Colleges of Physicians, Psychiatrists and General Practitioners. London: RCP, 1996

4 Pinching AJ. Chronic fatigue syndrome. Prescribers J 2000;40:99-106

5 Ismail $\mathrm{K}$, Kent $\mathrm{K}$, Brugha T, et al. The mental health of UK Gulf War veterans: phase 2 of a two phase cohort study. BMJ 2002;325:576-81

\section{Asperger's syndrome}

The article by Professor James (January $2003 J R S M^{1}$ ) was of considerable interest to me, though as a surgeon I cannot claim expert knowledge of mental processes. Asperger's syndrome appears to be a higher form of autism with full possession of intellectual faculties, as possibly exemplified by his examples of Newton, Einstein and Cavendish, but with an inability to form social and emotional bonds. I used to be a member of Mensa but left after realizing that $90 \%$ of the members were incapable of maintaining their end of a conversation and had difficulty in expressing any personal warmth; the only emotion I ever encountered was naked aggression.

Doctors like to wrap an insoluble problem in a syndrome because it gives them the satisfaction of pigeonholing a patient and restores their authority, enabling them to say 'You have X syndrome but there is no treatment' rather than confess they are completely at a loss. This satisfies patients as well, who are more than likely to wear their label as a badge of pride. I think that Asperger was only describing a variant of normal. If it is an abnormal state, there must be thousands of cases in this country, myself included.

\section{Ivor Schraibman}

Oakley House, Beaufort Avenue, Sale M33 3WL, UK

\section{REFERENCE}

1 James I. Singular scientists. J R Soc Med 2003;96:36-9

\section{Outpatient clinic: where is the delay?}

Mr Patel and his colleagues (December $2002 J_{R S M}^{1}$ ) discuss the pattern of work in a urology outpatient clinic. It is disturbing that so little time (4.8 minutes) is actually spent with the patient during consultations, and more so that this has decreased so much in the recent past. A notable observation is that $27 \%$ of patients did not keep their appointments. If they had, the workload would have been even greater. If the missing patients had arrived and had required on average the same amount of time with the consultant, then the clinic would have been 51 minutes longer - or, if the clinic could not be extended, the time spent with each patient would come down to only 3.5 minutes. This strengthens the arguments of the authors regarding improving efficiencies and investment in staff and training.

\section{Stephen Gordon}

Barnaby Chappell

Department of Urology, Brighton and Sussex University, Brighton, UK E-mail: steveg543@yahoo.co.uk

\section{How objective are systematic reviews?}

Dr Linde and Dr Willich (January 2003 JRSM ${ }^{1}$ ) have done a great service to the medical community by showing us how systematic reviews (SRs) can differ confusingly regarding a range of methodological aspects. As they point out, SRs are designed to avoid biases and make conclusions as objective as possible. Given the diversity of the SRs analysed, I was impressed with the level of agreement many of them reached in their conclusions. Table 1 summarizes five subject areas where our own SRs were cited. The concordance of the conclusions is stunning. 


\begin{tabular}{|c|c|c|}
\hline Subject area & First author (year) [Ref]* & Verbatim conclusion $^{\dagger}$ \\
\hline Homeopathic arnica & $\begin{array}{l}\text { Lüdke (1991) [48] } \\
\text { Ernst (1998) [47] }\end{array}$ & $\begin{array}{l}\text { '... efficacy ... must be interpreted with utmost care' } \$ \\
\text { [Efficacy is] 'not supported by rigorous clinical trials' }\end{array}$ \\
\hline Garlic for hypercholesterolaemia & $\begin{array}{l}\text { Lawrence (2000) [35] } \\
\text { Stevinson (2000) [34] }\end{array}$ & $\begin{array}{l}\text { 'Garlic ... [has a] small positive effect on lipids' } \\
\text { 'Garlic is superior to placebo ...., however, the size of the } \\
\text { effect is small' }\end{array}$ \\
\hline Peppermint for irritable bowel syndrome & $\begin{array}{l}\text { Jailwala (2000) [41] } \\
\text { Pittler (1998) [40] }\end{array}$ & $\begin{array}{l}\text { 'Peppermint oil ... requires further investigation' } \\
\text { '... peppermint oil ... has so far not been established } \\
\text { beyond reasonable doubt' }\end{array}$ \\
\hline Acupuncture for tinnitus & $\begin{array}{l}\text { Dobie (1999) [25] } \\
\text { Park (2000) [26] }\end{array}$ & $\begin{array}{l}\text { 'No treatment can yet by considered well established' } \\
\text { 'Acupuncture ... has not been demonstrated to be } \\
\text { efficacious' }\end{array}$ \\
\hline Ginkgo for intermittent claudication & $\begin{array}{l}\text { Moher (2000) [27] } \\
\text { Pittler (2000) [28] }\end{array}$ & $\begin{array}{l}\text { '...Ginkgo ... [is] slightly more effective than placebo' } \\
\text { 'Ginkgo is superior to placebo' }\end{array}$ \\
\hline
\end{tabular}

${ }^{*}$ Reference numbers according to article by Linde and Willich $\dagger$ From abstracts of published article (where applicable) $\ddagger$ My translation

There are exceptions, of course. The prime example is acupuncture for back pain, where we have published a 'positive' 2 and others a largely 'negative' $\mathrm{SR}^{3}$. The difference is, however, readily explicable: we pooled the data from all trials where this was possible ${ }^{2}$ while van Tulder et al. ${ }^{2}$ basically relied on a vote count. If studies tend to be small and produce non-significant positive trends, pooling will generate a positive overall result, while votecounts will yield a negative one.

And then there is homeopathy, which is perhaps the most controversial subject of all. Linde et al. have published their landmark SR concluding that 'clinical effects of homeopathy are not completely due to placebo' 4 . Two years later they cast considerable doubt on this by reanalysing the data and concluding that 'there was clear evidence that studies with better methodological quality tended to yield less positive results' ${ }^{5}$. I have recently reviewed all eleven SRs of homeopathy published since Lind's meta-analysis ${ }^{4}$. This collective evidence led me to conclude that 'the best clinical evidence for homeopathy available to date does not warrant positive recommendations for its use in clinical practice'6.

\section{Edzard Ernst}

Complementary Medicine, Peninsula Medical School, Universities of Exeter \& Plymouth, 25 Victoria Park Road, Exeter, Devon EX2 4BN, UK

\section{REFERENCES}

1 Linde K, Willich SN. How objective are systematic reviews? Differences between reviews in complementary medicine. $J$ R Soc Med 2003;96: $17-22$

2 Ernst E, White AR. Acupuncture for back pain. A meta-analysis of randomized controlled trials. Arch Intern Med 1998;158:2235-41

3 van Tulder MW, Cherkin DC, Berman B, Lau L, Koes BW. Acupuncture for low back pain. Cochrane Library 2000
4 Linde K, Clausius N, Ramirez G, et al. Are the clinical effects of homoeopathy placebo effects? A meta-analysis of placebo-controlled trials. Lancet 1997;350:834 43

5 Linde K, Scholz M, Ramirez G, Clausius N, Melchart D, Jonas WB. Impact of study quality on outcome in placebo controlled trials of homoeopathy. J Clin Epidemiol 1999;52:631-6

6 Ernst E. A systematic review of systematic reviews of homeopathy. Br J Clin Pharmacol 2002;54:577-82

\section{Capacity and consent}

Dr Jackson and Dr Warner (December 2002 JRSM $^{1}$ ) make an assessment of the knowledge of capacity and consent issues across different medical specialties. I am not surprised by the deficits they identify with the results as attendance to many seminars looking at capacity and consent. More worrying is my personal experience as a psychiatric trainee. When on call, both as a senior house officer and as a specialist registrar, I have received requests from nonpsychiatric colleagues to implement the Mental Health Act in order to carry out medical or surgical treatment in patients who either refused or clearly were not able to consent to it. Even in teaching sessions for a mixed-specialty group this issue is not clearly discussed. I would like to see education in the use and limitations of the Mental Health Act along with the training regarding issues of capacity and consent.

I Agell

Leeds General Infirmary, Leeds, UK

\section{REFERENCE}

1 Jackson E, Warner J. How much do doctors know about consent and capacity? J R Soc Med 2002;95:601-3 


\section{Noise exposure in motorcyclists}

As an ear, nose and throat surgeon and a motorcyclist I have both a professional and a personal interest in the matter discussed by $\mathrm{Mr}$ McCombe (January $2003 \mathrm{JRSM}^{1}$ ). For some while now I have used custom-made ear plugs supplied by Elacin which were, I believe, originally developed in collaboration with the Dutch motorcycle police. These are comfortable for long periods, have effectively abolished the temporary threshold shift and tinnitus which used to be inevitable consequences of a long journey and seem not to impair the appreciation of ambient traffic sounds which is essential for personal survival. I am sure that helmet manufacturers should be persuaded or obliged to include some measure of the 'noisiness' of their helmets in the specification they submit for their kite marking and other safety standards.

\section{Andrew Keith}

Victoria Hospital, Blackpool, UK

\section{REFERENCE}

1 McCombe A. Hearing loss in motorcyclists: occupational and medicologal aspects. J R Soc Med 2003;96:7-9

\section{The philosophy of science}

Dr Harper's paper (January $2003 J R S M^{1}$ ) refers to the philosophy of science. It is disappointing to see no mention of a giant of 20th century philosophy, Sir Karl Popper. The philosophy of science was an area in which he made groundbreaking observations. Harper dwells on Kuhn who, worthy though he may be, compares with Popper as a foothill does to Mount Everest. Although he was best known as a philosopher of science, Popper's ideas give insights which advance way beyond the confines of science and this also puts him on a different plane. The philosophy of science without Popper is like Hamlet without the Prince.

\section{Anthony Eisinger}

54 Wimpole Street, London W1, UK

\section{REFERENCES}

1 Harper M. Philosophy for physicians. J R Soc Med 2003;96:40-5

2 Popper KR. The Logic of Scientific Discovery. London: Hutchinson, 1972

\section{Michelangelo and medicine}

John Seamer (December 2002 JRSM ${ }^{1}$ ) believes that the statue of David is left-handed as the sling is over the left shoulder. However, the pose of the statue is almost contemplative, as if he was studying Goliath, and does not suggest an imminent attack, in which case the position of the sling is immaterial and the larger size of the right hand should indicate right-handedness.

Frank Jackson

Edmonton, Alberta, Canada

\section{REFERENCE}

1 Seamer J. Michelangelo and medicine. J R Soc Med 2002;95:530 